\title{
PERSEPSI MASYARAKAT TENTANG KEBERADAAN MONYET EKOR PANJANG (Macaca fascicularis) DI DESA TUMBANG NUSA KABUPATEN PULANG PISAU KALIMANTAN TENGAH
}

\author{
(Public Perception of the Existence of the Long Tail Monkey (Macaca fascicularis) \\ in the Village of Tumbang Nusa of the District of Pulang Pisau of Central Kalimantan)
}

\author{
ISE AFITAH
}

\author{
Program Studi Kehutanan Fakultas Pertanian dan Kehutanan \\ Universitas Muhammadiyah Palangkaraya \\ JI. RTA Milono Km.1,5 Palangka Raya, Kalimantan Tengah 73111 \\ e-mail : afitah78@yahoo.com
}

\begin{abstract}
This study aims to determine the perception that people living around the forest areas in conserving forest habitat preservation especially of the long tail monkey (Macaca fascicularis). The expected results of the research conducted is the obtaining of information materials for relevant agencies for the preservation of the long tail monkey (Macaca fascicularis) by people in Tumbang Nusa as the basis for conservation.

Communities around the region are not yet aware of the importance of wildife reserves mainly habitat the long tail monkey (Macaca fascicularis). Local communities know of the existence of the long tail monkey (Macaca fascicularis) in their area which is about $84.3 \%$ and most of them know by direct presence of the long tail monkey (Macaca fascicularis) in the amount of $67.1 \%$ but the local people do not know about nature conservation and habitat the long tail monkey ie $71.4 \%$ and most of them without intentional conduct habitat destruction and very little involved in conservation of the long tail monkey, including the open field activity of $60 \%$, logging $52.9 \%$ and it does not matter to extinguish the flames during a wildfire that is $82.9 \%$.

It needs a continuous program and continuous from the relevant stakeholders to provide socialization to the local communities so that people can know about the conservation of nature and habitat of the long tail monkey, in the short term is necessary to rescue of the long tail monkey habitat that has been there from further damage.
\end{abstract}

Keywords: public perception, wildlife

\section{ABSTRAK}

Penelitian ini bertujuan untuk mengetahui persepsi masyarakat yang bermukim disekitar kawasan hutan dalam menjaga kelestarian hutan khususnya kelestarian habitat monyet ekor panjang (Macaca fascicularis). Hasil yang diharapkan dari penelitian yang dilakukan adalah diperolehnya bahan informasi bagi instansi terkait untuk pelestarian monyet ekor panjang oleh masyarakat di Tumbang Nusa sebagai dasar konservasi.

Masyarakat di sekitar kawasan belum menyadari akan pentingnya keberadaan suaka margasatwa terutama habitat monyet ekor panjang. Masyarakat setempat mengetahui akan adanya monyet ekor panjang di daerah mereka yaitu sekitar $84,3 \%$ dan kebanyakan mereka mengetahuinya dengan melihat secara langsung keberadaan monyet ekor panjang yaitu sebesar $67,1 \%$ akan tetapi masyarakat setempat tidak mengetahui tentang pelestarian alam dan habitat monyet ekor panjang yaitu $71,4 \%$ dan sebagian besar mereka tanpa disengaja melakukan kegiatan pengerusakan habitat dan sedikit sekali terlibat dalam upaya pelestaraian monyet ekor panjang, diantaranya adalah kegiatan membuka ladang $60 \%$, melakukan penebangan 52,9\% dan tidak peduli untuk memadamkan api saat terjadi kebakaran lahan yaitu sebesar $82,9 \%$.

Perlu adanya program secara terus menerus dan berkesinambungan dari stakeholder terkait untuk memberikan sosialisasi kepada masyarakat setempat agar masyarakat dapat mengetahui tentang pelestarian alam dan habitat dari monyet ekor panjang, dalam jangka pendek perlu dilakukan penyelamatan habitat monyet ekor panjang yang telah ada dari kerusakan lebih lanjut.

Kata kunci : persepsi masyarakat, pelestarian 


\section{PENDAHULUAN}

Sumberdaya alam hayati dan ekosistemnya merupakan bagian terpenting dari sumberdaya alam yang terdiri dari alam hewani dan alam nabati, secara bersama-sama mempunyai fungsi dan manfaat sebagai unsur pembentuk lingkungan hidup, yang kehadirannya tidak dapat digantikan oleh sumberdaya alam non-hayati.

Satwa liar merupakan salah satu sumberdaya alam hayati yang dapat di manfaatkan secara lestari dan berkelanjutan, karena satwa liar merupakan sumberdaya alam hayati yang dapat diperbaharui atau terbarukan (renewable resources).

Sebagai upaya pelestarian monyet ekor panjang (Macaca fascicularis) adalah dengan melakukan perlindungan terhadap populasi dan habitat alaminya serta mempertahankannya sebagai satu bentuk kesatuan ekosistem yang utuh. Untuk mencapai keberhasilan tersebut, perlu adanya kesamaan persepsi dari semua pihak tentang pentingnya tindakan pelestarian terhadap monyet ekor panjang (Macaca fascicularis). Selain itu, diperlukan pula dukungan dan partisipasi dari masyarakat, khususnya yang tinggal di sekitar habitat satwa tersebut.

Secara umum tujuan penelitian adalah:untuk mengetahui persepsi masyarakat yang bermukim disekitar kawasan hutan dalam menjaga kelestarian hutan khususnya kelestarian habitat monyet ekor panjang (Macaca fascicularis)dari penelitian ini diharapkan dapat memberikan informasi bagi instansi terkait untuk pelestarian monyet ekor panjang (Macaca fascicularis)oleh masyarakat di Tumbang Nusa sebagai dasar konservasi.

\section{METODOLOGI}

\section{Lokasi dan Waktu Penelitian}

Penelitian ini dilaksanakan di Desa Tumbang Nusa Kecamatan Jabiren Raya Kabupaten Pulang Pisau Provinsi Kalimantan Tengah.Waktu yang dibutuhkan dalam pelaksanaan penelitian ini secara efektif dilaksanakan selama 3 (tiga) bulan yaitu pada bulan Agustus sampai Oktober 2016.

\section{Bahan dan Alat Penelitian}

Penelitian ini menggunakan bahan-bahan sebagai berikut : peta administratif tempat lokasi penelitian; data kependudukan daerah di sekitar kawasan habitat monyet ekor panjang (Macaca fascicularis). Adapun peralatan yang digunakan dalam penelitian ini adalah sebagai berikut: alat tulis menulis untuk pencatatan objek penelitian; kuisioner untuk pengolahan data primer; kamera, untuk dokumentasi penelitian.

\section{Prosedur Penelitian}

\section{Observasi Lapangan}

Merupakan kegiatan pengumpulan data yang dilakukan dengan cara pengamatan langsung di lapangan, sehingga dapat mendeskripsikan secara cermat dan terinci mengenai keadaan lapangan dan kegiatan masyarakat dimana kegiatan ini dilaksanakan.

2. Penentuan Sampel

Penelitian ini menggunakan meode penelitian survei menurut Singarimbun (1989), yaitu penelitian yang mengambil sampel dari satu populasi dan menggunakan kuisioner sebagai alat pengumpul data yang pokok. Penentuan sampel merupakan langkah penting dalam penelitian, penentuan sampel dalam penelitian ini berdasarkan jumlah sampel di lapangan 
yaitu dengan cara purposive sampling (penentuan masyarakat secara sengaja), yakni dipilih langsung masyarakat yang berdekatan dengan habitat monyet ekor panjang (Macaca fascicularis).

Sampel masyarakat ditentukan dengan syarat berumur produktif, yaitu minimal 18 tahun, yang mana pada umur ini responden cukup memahami semua pertanyaan-pertanyaan yang diberikan. Jumlah sampel masyarakat ditentukan berdasarkan Levin dan Fox (1991) dengan persamaan sebagai berikut :

$$
n=\frac{Z^{2} \pi(1-\pi)}{M E}
$$

Keterangan :

$\mathrm{n} \quad$ : jumlah sampel

Z : nilai $\mathbf{Z}$ pada tingkat kepercayaan $(\alpha)$ yang diinginkan

$\pi \quad$ : proporsi populasi

ME : batas kesalahan yang dapat diterima dari rata-rata populasi

Jika ditentukan $\alpha=5 \%, Z=1,96, \pi=50 \%$, dan $\mathrm{ME}=12 \%$, maka jumlah sampel pada objek penelitian ini minimal sebesar:

$$
\begin{aligned}
\mathrm{n}= & \left(1,96^{2} \times 0,5 \times 0,5\right) /\left(0,12^{2}\right)=66,69= \\
& 67 \text { responden }
\end{aligned}
$$

Untuk mengetahui karakteristik masyarakatnya dilakukan wawancara dengan responden yang terpilih.

\section{Tahap Pengumpulan Data}

Dalam tahapan ini dilakukan pengumpulan data, teknik yang digunakan adalah metode wawancara terhadap responden yang berasal dari masyarakat di sekitar habitat monyet ekor panjang (Macaca fascicularis). Selain metode tersebut, digunakan pula metode telaahan dokumentasi (data sekunder) yang diperoleh dari berbagai sumber dan pengamatan langsung di lapangan.
Data penelitian yang akan dikumpulkan dibedakan berdasarkan sumber data yang dibutuhkan, yaitu:

\section{Data sekunder}

Data ini diperoleh dari instansi pemerintah serta lembaga-lembaga yang relevan dengan penelitian, diperoleh melalui studi dokumentasi atau wawancara personal. Jenis datanya berupa : batas dan luas wilayah, iklim, topografi, jumlah kepala keluarga, jumlah penduduk, struktur umur, pendidikan, mata pencarian, prasarana desa dan kelembagaan.

2. Data primer

Data ini bersumber dari penduduk yang bermukim disekitar kawasan habitat monyet ekor panjang (Macaca fascicularis), yang dikumpulkan melalui metode wawancara sesuai dengan pertanyaan yang telah disiapkan dalam daftar isian (kuisioner).

Secara garis besar lingkup data penelitian ditampilkan pada Tabel 1.

\section{Analisis Data}

Teknik analisis data dalam penelitian ini menggunakan metode skala guttman yang digunakan untuk jawaban yang bersifat jelas (tegas) dan konsisten, kemudian dianalisis dengan perhitungan persentase (\%). Menurut Riduwan (2009), bahwa bila suatu penelitian bertujuan mendapatkan gambaran atau menemukan sesuatu sebagai adanya tentang objek yang diteliti maka teknis-teknis yang yang dibutuhkan cukup dengan persentase kuantitatif.

Selain itu penelitian ini juga menggunakan metode kualitatif, bertujuan untuk mencari kebenaran data di lapangan. Penelitian kualitatif digunakan jika masalah belum jelas, untuk mengetahui makna yang tersembunyi, untuk 
Tabel 1. Garis besar lingkup data penelitian

\begin{tabular}{llll}
\hline \multicolumn{1}{c}{ Data yang Dikumpulkan } & $\begin{array}{c}\text { Jenis Data dan Teknik } \\
\text { Pengumpulan Data }\end{array}$ & \multicolumn{1}{c}{ Sumber Data } & $\begin{array}{c}\text { Keluaran yang } \\
\text { Diharapkan }\end{array}$ \\
\hline $\begin{array}{l}\text { 1. Data biogeofisik: batas dan } \\
\text { luas wilayah, topografi, jenis } \\
\text { tanah, flora dan fauna. }\end{array}$ & $\begin{array}{l}\text { Sekunder - Observasi } \\
\text { dan studi dokumentasi }\end{array}$ & $\begin{array}{l}\text { Peta, Foto, Monografi } \\
\text { Kecamatan dan } \\
\text { Monografi Desa }\end{array}$ & $\begin{array}{l}\text { Gambaran umum } \\
\text { biogeofisik lokasi } \\
\text { penelitian }\end{array}$ \\
$\begin{array}{l}\text { 2. Data sosial ekonomi: jumlah } \\
\text { penduduk, struktur umur, } \\
\text { pendidikan serta mata } \\
\text { pencarian. }\end{array}$ & $\begin{array}{l}\text { Sekunder - Observasi } \\
\text { dan studi dokumentasi }\end{array}$ & $\begin{array}{l}\text { Peta, Foto, Monografi } \\
\text { Kecamatan dan }\end{array}$ & $\begin{array}{l}\text { Gambaran umum } \\
\text { sosial ekonomi } \\
\text { masyarakat }\end{array}$ \\
$\begin{array}{l}\text { 3. Persepsi masyarakat terhadap } \\
\begin{array}{l}\text { Ppaya pelestarian monyet ekor } \\
\text { panjang (Macaca fascicularis) }\end{array}\end{array}$ & Primer - Wawancara & Responden & $\begin{array}{l}\text { Gambaran umum } \\
\text { persepsi } \\
\text { masyarakat }\end{array}$ \\
\hline
\end{tabular}

memahami interaksi soaial, untuk mengembangkan teori, untuk memastikan kebenaran data dalam penelitian kualitatif yang dilaksanakan pada penelitian ini adalah:

1. Wawancara

Teknik wawancara yang digunakan dalam penelitian kualitatif adalah wawancara mendalam untuk memperoleh keterangan, untuk tujuan penelitian dengan cara tanya jawab sambil bertatap muka antara pewawancara dengan informan atau orang yang diwawancara.

2. Observasi

Metode pengumpulan data yang digunakan untuk menghimpun data penelitian melalui pengamatan dan penginderaan dimana peneliti benar-benar terlibat dalam keseharian responden.

3. Dokumen

Sejumlah fakta dan data tersimpan dalam bahan yang berbentuk dokumentasi. Sebagian besar data yang tersedia adalah berbentuk surat-surat, catatan harian, laporan dan sebagainya. Berdasarkan hal tersebut, untuk mencari dan menghitung besarnya persentase jawaban responden maka peneliti menggunakan rumus sebagai berikut:

$$
P=\frac{F}{N} \times 100 \%
$$

Keterangan:

$\mathrm{P} \quad=$ Persentase yang dicari

$\mathrm{F} \quad=$ Frekuensi jawaban responden

$\mathrm{N}=$ Jumlah sampel

$100 \%=$ Bilangan pengali tetap

Peneliti menggunakan kriteria pedoman menurut Winarno (1988), dengan penilaian skor sebagai berikut:

$\begin{array}{ll}\text { Sangat Baik } & =80-100 \% \\ \text { Baik } & =60-80 \% \\ \text { Cukup Baik } & =40-60 \% \\ \text { Kurang Baik } & =20-40 \% \\ \text { Sangat Kurang } & =10-20 \%\end{array}$

HASIL DAN PEMBAHASAN

\section{Keadaan Umum Lokasi Penelitian}

Secara administratif Kecamatan Jabiren Raya termasuk dalam Pemerintahan Kabupaten Pulang Pisau. Propinsi Kalimantan Tengah. Jumlah Penduduk di Kecamatan Jabiren 
berjumlah 8.083 jiwa, dengan luas wilayah $1.323 \mathrm{Km}^{2}$ dan terdapat delapan (8) desa yang terdiri dari desa Garung, Henda, Simpur, Sakakajang, Jabiren, Pilang, Tumbang Nusa, dan Tanjung Taruna.

Desa Tumbang Nusa merupakan salah satu diantara desa yang terdapat di Kecamatan Jabiren Raya, dengan jumlah penduduk 939 jiwa. Luas wilayah Desa Tumbang Nusa adalah $200 \mathrm{Km}^{2}$ dengan batas-batas wilayah sebagai berikut:

- Sebelah Barat berbatasan dengan Kelurahan Kalampangan

- Sebelah Timur berbatasan dengan Desa Pilang

- Sebelah Utara berbatasan dengan Hutan Negara dan Kabupaten Kapuas

- Sebelah Selatan berbatasan dengan Sei Sebangau

Topografi di wilayah Desa Tumbang Nusa merupakan rawa-rawa dengan ketinggian tempat berkisar $0-0,25$ meter di atas permukaan laut, yang mempunyai elevasi $0-8 \%$ serta dipengaruhi oleh pasang surut dan merupakan daerah yang mempunyai potensi banjir yang cukup besar, bahkan dimusim penghujan genangan air dapat mencapai \pm 1 meter di atas permukaan laut. Keadaan topografi daerah ini umumnya terdiri atas $85 \%$ datar, $10 \%$ bergelombang dan $5 \%$ berbukit, $75 \%$ merupakan rawa-rawa atau sekitar $19.000 \mathrm{Ha}$ dan 25\% merupakan tanah kering. Jenis tanah yang terdapat di wilayah Desa Tumbang Nusa ini adalah organosol, podsolik dan alluvial, sedangkan jenis batuannya terbentuk dari sedimen alluvial dan terumbu karang (Badan Perencanaan Daerah, 2003 dalam Fitriyah, 2012).
Berdasarkan klasifikasi tipe iklim Schmidt dan Ferguson, desa Tumbang Nusa termasuk tipe iklim A dengan nilai $Q=3,82 \%$. Curah hujan pada wilayah ini relatif tinggi sepanjang tahunnya dengan jumlah rata-rata curah hujan bulanan 252,0 $\mathrm{mm}$ dan rata-rata curah hujan tahunnya $3024,1 \mathrm{~mm}$. Curah hujan relatif tinggi terjadi pada bulan Oktober sampai bulan Desember dan curah hujan relatif rendah terjadi sekitar bulan Juni sampai dengan akhir bulan september. Suhu ratarata perbulannya adalah $82 \%$ (Badan Pusat Statistik Kota Palangka Raya, 2004).

Wilayah Desa Tumbang Nusa khususnya di Selat Nusa merupakan hutan rawa gambut dimana sebagain telah beralih fungsi menjadi kebun karet, rotan irit dan rotan taman di sepanjang kiri kanan sungai.

\section{Deskripsi Mengenai Responden}

Karakteristik jumlah responden (jumlah masyarakat sekitar habitat monyet ekor panjang (Macaca fascicularis)) berjumlah 70 orang. Karakteristik masyarakat disajikan pada Tabel 2.

Karakteristik sosio-demografi masyarakat sekitar habitat monyet ekor panjang (Macaca fascicularis) yang berhasil disurvei dalam penelitian ini meliputi umur, pendidikan, pekerjaan dan pendapatan. Berdasarkan umur responden rata-rata berumur 43 tahun, berjenis kelamin lakilaki sebesar $74,3 \%$ dan perempuan $25,7 \%$.

Dilihat dari faktor pendidikan, masyarakat di sekitar habitat monyet ekor panjang (Macaca fascicularis) sebagian besar berpindidikan SD $(32,8 \%)$ diikuti masyarakat yang berpendidikan SMP $(21,4 \%)$, berpendidikan DII/DIII $(17,2 \%)$ dan berpendidikan SMA dan S1 masing-masing $14,3 \%$. 
Tabel 2. Karakteristik masyarakat Tumbang Nusa

\begin{tabular}{|c|c|c|c|}
\hline No. & Karakteristik & Masyarakat & $\%$ \\
\hline 1. & Umur rata-rata & 43 (Tahun) & \\
\hline \multirow[t]{3}{*}{2.} & Jenis Kelamin & & \\
\hline & a. Laki-Laki & 52 & 74,3 \\
\hline & b. Perempuan & 18 & 25,7 \\
\hline \multirow[t]{6}{*}{3.} & Pendidikan & & \\
\hline & a. $\mathrm{S} 1$ & 10 & 14,3 \\
\hline & b. DII/DIII & 12 & 17,2 \\
\hline & c. SMA/SLTA & 10 & 14,3 \\
\hline & d. SMP & 15 & 21,4 \\
\hline & e. SD & 23 & 32.8 \\
\hline \multirow[t]{5}{*}{4.} & Pekerjaan & & \\
\hline & a. Petani & 24 & 34,3 \\
\hline & b. Swasta & 25 & 35,7 \\
\hline & c. Pegawai & 15 & 21,4 \\
\hline & d. Mahasiswa/Pelajar & 6 & 8,6 \\
\hline \multirow[t]{5}{*}{5.} & Pendapatan/bulan (Rpx1.000/bulan) & & \\
\hline & a. $0-500$ & 4 & 5,7 \\
\hline & b. $500-1.000$ & 46 & 65,7 \\
\hline & c. $1.000-1.500$ & 15 & 21,4 \\
\hline & d. $>1.500$ & 5 & 7,2 \\
\hline
\end{tabular}

Berdasarkan jenis pekerjaan, masyarakat di sekitar habitat monyet ekor panjang (Macaca fascicularis) paling banyak swasta $35,7 \%$ kemudian petani sebesar $34,3 \%$, diikuti pegawai $21,4 \%$ dan pelajar/mahasiswa sebesar $8,6 \%$.

Dilihat dari pendapatan dapat ditunjukkan bahwa $71,4 \%$ masyarakat merupakan kelompok berpendapatan kurang dari Rp 1.000.000,-/bulan dan sisanya $28,6 \%$ merupakan responden berpendapatan lebih besar dari Rp 1.000.00,-.

\section{Persepsi Masyarakat}

1. Persepsi masyarakat tentang keberadaan monyet ekor panjang (Macaca fascicularis)

Untuk mengetahui pendapat masyarakat sekitar tentang keberadaan monyet ekor panjang di daerah mereka dapat dilihat pada Tabel 3.

Berdasarkan frekuensi jawaban responden dari 70 orang masyarakat tentang keberadaan monyet ekor panjang (Macaca fascicularis) pada Tabel 3 dapat dijelaskan bahwa masyarakat setempat mengetahui akan adanya monyet ekor panjang di daerah mereka bisa dilihat sekitar 84,3\% masyarakat mengetahuinya dan kebanyakan mereka mengetahuinya dengan melihat secara langsung keberadaan monyet ekor panjang tersebut $67,1 \%$. Akan tetapi saat ditanya tentang ciri-ciri fisik dari monyet ekor panjang secara detail hanya 60\% saja masyarakat dapat mengetahuinya. Menurut masyarakat setempat keberadaan monyet ekor panjang tidak mengganggu aktivitas mereka yaitu sekitar $71,4 \%$ dan sekitar $77 \%$ masyarakat setempat senang dengan keberadaan monyet ekor panjang di daerah mereka. 
Tabel 3. Persepsi masyarakat tentang keberadaan monyet ekor panjang

\begin{tabular}{cllcc}
\hline No. & \multicolumn{1}{c}{ Pertanyaan } & \multicolumn{1}{c}{ Jawaban } & Jumlah & $\%$ \\
\hline 1 & Apakah Anda mengetahui tentang & a. Ya & 59 & 84,3 \\
& keberadaan monyet ekor panjang & b. Tidak & 11 & 15,7 \\
2 & Dari mana Anda Mengetahui tentang & a. Lihat langsung & 47 & 67,1 \\
& adanya monyet ekor panjang & b. Teman & 3 & 32,9 \\
\multirow{2}{*}{3} & Apakah Anda mengetahui ciri-ciri fisik & a. Ya & 42 & 60,0 \\
& dari moyet ekor panjang & b. Tidak & 28 & 40,0 \\
4 & Menurut Anda, apakah keberadaan & a. Ya & 20 & 28,6 \\
& $\begin{array}{l}\text { monyet ekor panjang mengganggu } \\
\text { masyarakat sekitar }\end{array}$ & b. Tidak & 50 & 71,4 \\
5 & $\begin{array}{l}\text { Apakah Anda senang dengan } \\
\text { keberadaan monyet ekor panjang } \\
\text { disekitar Anda }\end{array}$ & a. Ya & 16 & 22,9 \\
\hline
\end{tabular}

2. Persepsi masyarakat tentang pelestarian habitat monyet ekor panjang (Macaca fascicularis)

Jawaban para responden dapat dilihat pada Tabel 4 bahwa masyarakat setempat tidak mengetahui tentang pelestarian alam dan habitat monyet ekor panjang yaitu $71,4 \%$ dan sebagian besar mereka tanpa disengaja melakukan kegiatan pengerusakan habitat dan sedikit sekali terlibat dalam upaya pelestraian dari monyet ekor panjang, diantaranya adalah kegiatan membuka ladang 60\%, melakukan penebangan $52,9 \%$ dan tidak peduli untuk memadamkan api saat terjadi kebakaran lahan yaitu $82,9 \%$.

Faktor penyebab kerusakan habitat monyet ekor panjang (Macaca fascicularis) terutama diakibatkan oleh adanya aktivitas masyarakat disekitar hutan. Beberapa kegiatan masyarakat yang teridentifikasi yang berakibat pada tekanan terhadap populasi monyet ekor panjang (Macaca fascicularis) adalah:

\section{Perambahan Hutan}

Gangguan habitat dari monyet ekor panjang (Macaca fascicularis) terutama dijumpai pada habitat hutannya yang sangat mempengaruhi kehidupan monyet ekor panjang (Macaca fascicularis) dengan adanya pembukaan tegakan hutan untk dijadikan lahan perkebunan yang sulit untuk dihindari.

Berdasarkan hasil wawancara dengan masyarakat setempat menunjukkan bahwa sebagian besar masyarakat melakukan perambahan hutan untuk membuka ladang/kebun di dalam hutan karena lahan yang mereka miliki hasilnya tidak mencukupi untuk memenuhi kebutuhan hidup keluarga mereka, sebagaimana terlihat pada Tabel 4 . Apabila hal ini terus berjalan maka kemungkinan monyet ekor panjang akan pindah habitat, mencari habitat yang cocok untuk kehidupannya. Jadi alih fungsi hutan menjadi penggunaan lain bila terus berlanjut akan menyebabkan fragmentasi habitat ke dalam kantong-kantong habitat yang kecil dan 
Tabel 4. Persepsi masyarakat tentang pelestarian habitat monyet ekor panjang

\begin{tabular}{cllcr}
\hline No. & \multicolumn{1}{c}{ Pertanyaan } & Jawaban & Jumlah & $\%$ \\
\hline 1. & Apakah Anda mengetahui tentang & a. Ya & 20 & $28,6 \%$ \\
& pelestarian alam dan habitatnya & b. Tidak & 50 & $71,4 \%$ \\
2. & Apakah Anda pernah membuka & a. Ya & 42 & $60 \%$ \\
& $\begin{array}{l}\text { ladang di sekitar kawasan hutan di } \\
\text { habitat monyet ekor panjang }\end{array}$ & b. Tidak & 28 & $40 \%$ \\
3. & Apakah Saudara pernah melakukan & a. Ya & 37 & 52,9 \\
& penebangan di sekitar kawasan hutan & b. Tidak & 33 & 47,1 \\
4i habitat monyet ekor panjang & Apa Anda ikut terlibat memadamkan & a. Ya & 12 & $17,1 \%$ \\
& api saat terjadinya kebakaran hutan & b. Tidak & 58 & $82,9 \%$ \\
5. & Menurut Anda kawasan hutan di & a. Negara & 22 & $31,4 \%$ \\
& sekitar Anda itu milik siapa & b. Umum & 48 & $68,6 \%$ \\
\hline
\end{tabular}

terisolir dari kantong-kantong habitat lainnya. Isolasi habitat ini akan menghilangkan aksesibilitas monyet ekor panjang dalam mencari makanannya sehingga dapat menghambat proses reproduksi dan dalam jangka panjang akan menyebabkan penurunan genetik populasi yang bersangkutan akibat terjadinya inbreeding.

\section{Penebangan}

Gangguan pada habitat monyet ekor panjang selain perambahan hutan adalah penebangan tegakan hutan untuk kayu pertukangan, pembuatan perahu maupun untuk kayu bakar. Umumnya pohon-pohon yang ditebang adalah pohon-pohon yang digunakan oleh monyet ekor panjang dalam melakukan aktivitasnya. Selain fungsi tersebut di atas, pohon-pohon yang ditebang juga berfungsi sebagai sumber pakan bagi monyet ekor panjang.

Meningkatnya tekanan masyarakat terhadap populasi monyet ekor panjang baik langsung maupun tidak langsung disebabkan oleh kondisi soaial ekonomi. Tingkat pendidikan yang rendah dan kesejahteraan yang kurang diduga menjadi penyebab penekanan tersebut. Mereka lebih peduli terhadap hal-hal yang dapat langsung meningkatkan perekonomian, seperti perluasan lahan budidaya, pemanenan kayu dan hasil hutan lainnya serta konsumsi satwa liar untuk mencukupi kebutuhan mereka.

3. Kebakaran Lahan

Terjadinya bencana alam kebakaran lahan dan hutan pada saat musim kemarau tiba turut menyumbang tekanan terhadap habitat monyet ekor panjang karena habitat tempat tinggal dan tempat aktivitas serta sumber makanan mereka terbakar. Apabila hal ini dibiarkan terus menerus tanpa adanya upaya pencegahan dan kepedulian dari masyarakat sekitar, maka monyet ekor panjang ini lama kelamaan akan habis populasinya karena mati atau juga karena berpindah tempat.

Tingkat pendidikan formal masyarakat sekitar habitat secara umum adalah rendah karena sebagian besar hanya sampai pada Sekolah Dasar saja (seperti terlihat pada Tabel 2.). 
Berhasil tidaknya upaya pelestarian habitat pada suatu kawasan tertentu sangat ditentukan oleh kepedulian masyarakat di sekitarnya. Gangguan utama yang ditemui adalah aktivitas manusia di sekitar kawasan tersebut sebagaimana yang telah dikemukakan di atas.

Masyarakat di sekitar kawasan belum menyadari akan pentingnya keberadaan suaka margasatwa tersebut. Mereka berpendapat bahwa hutan beserta seluruh isinya adalah milik umum. Demikian juga selama penelitian berlangsung ditemukan adanya oknum-oknum di sekitar lokasi yang masih belum mengerti akan perlindungan alam, mereka tetap saja berprofesi ganda, sebagai abdi masyarakat dan juga menjadi dalang dalam pembukaan lahan dan penebangan kayu di dalam kawasan hutan habitat monyet ekor panjang (Macaca fascicularis) berada.

Kelemahan masyarakat desa pada umumnya adalah sumberdaya manusia yang rendah, sehingga di dalam melaksanakan atau memanfaatkan sumberdaya hutan selalu berpikir subsisten. Padahal sumberdaya hutan jika dikelola dengan baik dan lestari akan memeberikan manfaat yang sangat besar bagi masyarakat itu sendiri. Oleh karenanya, hendaknya masyarakat atau aparat desa meminta dan bermitra dengan pemerintah daerah yang didampingi dengan LSM/ stakeholder lainnya, di dalam peningkatan sumberdaya masyarakat.

Masyarakat yang bermukim di dalam dan di sekitar kawasan perlu dibina agar tidak mudah dimanfaatkan oleh oknum yang tidak bertanggungjawab dan agar masyarakat dapat memanfaatkan sumberdaya alam secara lestari.

\section{KESIMPULAN DAN SARAN}

\section{Kesimpulan}

Berdasarkan hasil peneitian dan pembahasan dapat ditarik beberapa kesimpulan sebagai berikut:

a. Masyarakat di sekitar kawasan belum menyadari akan pentingnya keberadaan suaka margasatwa tersebut.

b. Masyarakat setempat mengetahui akan adanya monyet ekor panjang (Macaca fascicularis) di daerah mereka $84,3 \%$ dan kebanyakan mereka mengetahuinya dengan melihat secara langsung keberadaan monyet ekor panjang (Macaca fascicularis) $67,1 \%$.

c. Masyarakat setempat tidak mengetahui tentang pelestarian alam dan habitat monyet ekor panjang yaitu $71,4 \%$ dan sebagian besar mereka tanpa disengaja melakukan kegiatan pengerusakan habitat dan sedikit sekali terlibat dalam upaya pelestaraian monyet ekor panjang, diantaranya adalah kegiatan membuka ladang 60\%, melakukan penebangan $52,9 \%$ dan tidak peduli untuk memadamkan api saat terjadi kebakaran lahan yaitu $82,9 \%$.

\section{Saran}

a. Perlu adanya program secara kontinu dari stakeholder terkait untuk memberikan sosialisasi kepada masyarakat setempat agar masyarakat dapat mengetahui tentang pelestarian alam dan habitat dari monyet ekor panjang. 
b. Dalam jangka pendek perlu dilakukan penyelamatan habitat monyet ekor panjang yang telah ada dari kerusakan lebih lanjut.

\section{DAFTAR PUSTAKA}

Badan Pusat Statistik Kabupaten Pulang Pisau https://pulpiskab.bps.go.id/linkTableDinamis /view/id/50 diakses tanggal 15 Oktober 2016, jam 11.00 wib

BPS Kota Palangka Raya, 2004. Pulang Pisau Dalam Angka 2004. Badan Pusat Statistik (BPS) Kota Palangka Raya. Palangka Raya.

Fitriyah Parasitawati, 2012. Potensi Monyet Ekor Panjang (Macaca fascicularis) di Selat Nusa Desa Tumbang Nusa Kabupaten Pulang Pisau Kalimantan Tengah. Fakultas Kehutanan. Universitas Muhammadiyah Palangkaraya. Tidak dipublikasikan.

Levin, J. and F.J. Alan 1991. Elementary Statistic in Social Research. Fifth Edition, Haper Collins Publishers Inc, New York.

MacKinnon, J.; K. MacKinnon; Graham Child dan Jim Thorsell, 1986. Pengelolaan Kawasan yang Dilindungi di Daerah Tropika. Gajah Mada University Press.

Riduwan, M.B.A. 2009. Penelitian Pemula Metode Kuantitif. Alfabeta. Bandung.

Singarimbun, M. 1989. Metode dan Proses Penelitian. Metode Penelitian Survei (M. Singarimbun dan S. Effendi (Editor), LP3ES, Jakarta. 336 hal.

Winarno Suracman, 1998. Paper, Thesis, Disertasi. Bandung 